\title{
EFECTOS LEGALES EN ESPAÑA DE LAS EXPROPIACIONES DE BIENES INMUEBLES EN CUBA. UN FASCINANTE VIAJE POR LA GEOPOLÍTICA Y EL DERECHO INTERNACIONAL PRIVADO
}

\author{
LEGAL EFFECTS IN SPAIN OF EXPROPRIATIONS IN CUBA. \\ A FASCINATING JOURNEY THROUGH GEOPOLITICS AND \\ PRIVATE INTERNATIONAL LAW
}

\author{
JaVier Carrascosa González \\ Catedrático de Derecho internacional privado \\ Universidad de Murcia \\ ORCID ID: 0000-0002-0347-7985
}

Recibido: 17.07.2020 / Aceptado: 23.07.2020

DOI: https://doi.org/10.20318/cdt.2020.5610

\begin{abstract}
Resumen: El presente trabajo, mediante un análisis del auto de la audiencia provincial de las Islas Baleares de fecha 18 marzo 2020, aborda la cuestión de la competencia internacional de los tribunales españoles para conocer de los litigios por daños derivados de expropiaciones y confiscaciones de bienes verificadas en otros países. Este estudio pone de relieve la necesidad de perfilar adecuadamente la excepción de inmunidad de jurisdicción, así como la importancia de realizar una calificación correcta de la acción. Del mismo modo, se muestra también que España carece de una normativa como la Ley Helms-Burton vigente en los Estados unidos de América.

Palabras clave: Expropiaciones en el extranjero, Ley Helms-Burton, inmunidad de jurisdicción, daños, enriquecimiento injusto, declinatoria.

Abstract: This paper deals with the issue of the international jursidiction of the Spanish courts to hear litigation for damages arising from expropriations and confiscations of property verified in other countries. The study analyzes the order rendered by the Provincial Court of the Balearic Islands (Spain) dated March 18, 2020 and focuses on the the need to adequately outline the State immunity exception, as well as the importance of correctly characterisation of the issue. Similarly, it is also shown that Spain lacks legal regulations such as the Helms-Burton Act in force in the United States of America.

Keywords: Expropriations abroad, Helms-Burton Act, State immunity, damages, unjust enrichment.

Sumario: I. Revolución y expropiación, espacio y tiempo. II. El auto del Juzgado de Primera instancia de Palma de Mallorca de 2 septiembre 2019. El juzgado rechaza la competencia de los tribunales españoles. III. El auto de la Audiencia Provincial de las Islas Baleares de 18 marzo 2020. IV. Efectos jurídicos en España de una expropiación llevada a cabo en país extranjero. V. Reflexiones finales.
\end{abstract}




\section{Revolución y expropiación, espacio y tiempo}

1. Hace mucho tiempo en una galaxia muy lejana llamada Cuba..... tuvo lugar una revolución comunista, acompañada, entre otras cosas, de expropiaciones de inmuebles que eran propiedad de familias españolas ${ }^{1}$. Tales expropiaciones se llevaron a cabo sin ajustarse a un procedimiento legal y sin indemnización alguna. Fueron, más bien, auténticas confiscaciones, como explica E. SCHAEFFER ${ }^{2}$. En los vientos revolucionarios que todo lo arrasan, parece que tales actos iban a quedar para siempre impunes y que los perjudicados por la agresión a su derecho de propiedad nunca obtendrían reparación por aquellos actos y por los daños sufridos. En los huracanes caribeños desatados por la fuerza revolucionaria, la Ley parece quedar lejos y también parece que el tiempo, ese ladrón que todo se lo lleva, puede ocultar lo que pasó y que, por tanto, jamás volverá a hablarse de aquellas expropiaciones que tuvieron lugar ya hace más de cincuenta años en Cuba, la isla mayor de las Antillas.

2. El anterior parece un relato abstracto. Una reflexión nostálgica e histórica. Sin embargo, no es así. El supuesto abordado por el Auto JPI Palma Mallorca 2 septiembre 2019 demuestra que éste es un caso real $^{3}$. Unos sujetos españoles reclamaron, ante tribunales mallorquines, una indemnización por daños y perjuicios contra una cadena hotelera, -Hoteles Meliá-, cuya sede social se encuentra en Palma de Mallorca. Los actores estimaban que el gobierno cubano había llevado a cabo una expropiación ilegal de unos terrenos sitos en Cuba, que eran de propiedad de los hoy demandantes. Dicha ilegalidad la basaban los demandantes en el hecho de que la llamada "expropiación" no fue tal, sino un mero "acto de fuerza": sin procedimiento legal alguno, sin indemnización ninguna, sin audiencia de la parte perjudicada, los bienes fueron arrebatados a sus legítimos propietarios ${ }^{4}$.

Dichos terrenos, llamados "Ingenio Santa Lucía" y donde se cultivaba una deliciosa caña de azúcar cubana, estaban situados en la denominada "playa esmeralda". Lugar ideal para el turismo, pues ya sólo con ese nombre se genera expectación. Posteriormente, los terrenos fueron cedidos por el Estado cubano a Hoteles Meliá. Esta cadena hotelera construyó diversas instalaciones turísticas en los mismos y comenzó a explotar u rentabilizar el complejo turístico. Un buen negocio, qué duda cabe, con los pingües beneficios que proporcionan los turistas transoceánicos que desean disfrutar de las paradisíacas playas cubanas en un entorno muy bien equipado.

Sin embargo, resulta que la familia española que fuera propietaria de tales terrenos confiscados considera que Hoteles Meliá se está lucrando gracias dichos inmuebles cubanos que les fueron injusta e ilegalmente arrebatados por el gobierno de Cuba. Así las cosas, la familia en cuestión ejercita una acción ante los tribunales de Mallorca y solicitan una indemnización por daños y perjuicios a Hoteles Meliá. Los actores afirman que esta empresa se ha enriquecido durante años y siguen enriqueciéndose hoy gracias a lo que, en su opinión, fue una expropiación ilegal e injusta de los que fueran sus terrenos situados en Cuba. Con otras palabras, puede decirse que el gobierno revolucionario cubano confiscó unos terrenos a una familia española, que los entregó posteriormente a una empresa hotelera española, y que ésta los explota y extrae pingües beneficios. La familia española, perpleja, mira la vida pasar durante años y

\footnotetext{
${ }^{1}$ Este trabajo ha sido realizado en el marco del Proyecto de investigación "Los principios del Derecho Romano en el Derecho europeo del siglo XXI - Programa Logos Fundación BBVA de Ayudas a la Investigación en el Área de Estudios Clásicos" (IP Javier Carrascosa, Universidad de Murcia).

${ }^{2}$ E. Schaeffer, "Confiscation”, Enciclopedie Dalloz Droit international, vol.I, 1968, Paris, pp. 466-470. También G. VAN HeCKE, "Confiscations and the Conflict of Laws", ICLQ, 1951, pp. 349-357.

3 Auto JPI Palma Mallorca 2 septiembre 2019 [ECLI:ES:JPI:2019:6A].

${ }^{4}$ Un muy correcto análisis de este caso puede seguirse en J.L. IRIARTE ÁnGEL, "De nuevo sobre el problema de la competencia judicial internacional de los tribunales españoles para resolver litigios derivados de las nacionalizaciones cubanas. Reflexiones sobre el auto de la Audiencia Provincial de Palma de Mallorca (Sec. $3^{\mathrm{a}}$ ) de 18 de marzo de 2020, Bitácora Millennium, n.11, 2020 (http://www.millenniumdipr.com/ba-87-de-nuevo-sobre-el-problema-de-la-competencia-judicial-internacional-de-lostribunales-espanoles-para-resolver-litigios-derivados-de-las-nacionalizaciones-cubanas); J.L. IRIARTE ÁngEL, "La Ley HelmsBurton proyecta su sombra sobre la jurisprudencia española y la legislación de la Unión Europea", Bitácora Millennium, n.11, 2020 http://www.millenniumdipr.com/ba-86-la-ley-helms-burton-proyecta-su-sombra-sobre-la-jurisprudencia-espanola-y-lalegislacion-de-la-union-europea). Vid. también, de forma más modesta, J. CARrascosa GonZÁlez, ";Exprópiese! España, Cuba y playa esmeralda" en http://accursio.com/blog/?p=1112 (8 junio 2020).
} 
años y ve cómo transcurre el tiempo, pero piensa que esta vida es injusta. Se quedaron sin sus terrenos, nadie pagó nada por esa confiscación y ahora resulta que otra empresa, -casualidades de la vida, una empresa también española-, obtiene elevadas ganancias de los terrenos gracias a ese acto confiscatorio que fue, afirman, un completo desprecio a la legalidad. La imaginación es poderosa, sobre todo la imaginación de los profesores de Derecho internacional privado a la hora de diseñar casos prácticos de la asignatura. Sin embargo, por muy fecunda que ésta pueda llegar a ser, siempre la realidad supera toda imaginación. Aquí está la prueba, porque el caso referenciado es real.

\section{El auto del Juzgado de Primera instancia de Palma de Mallorca de 2 septiembre 2019. El juz- gado rechaza la competencia de los tribunales españoles.}

3. Ante la demanda de indemnización de daños y perjuicios por un enriquecimiento injusto, presentada ante los juzgados mallorquines, la primera línea de defensa de los demandados, Hoteles Meliá, cuya sede social se encuentra en Palma de Mallorca, es activar (i) una excepción declinatoria de jurisdicción y (ii) otra excepción de competencia internacional.

4. En primer lugar, los demandados se defienden con un arma procesal de destrucción masiva: la "inmunidad de jurisdicción". Entienden tales demandados que los tribunales españoles, de oficio, deben rechazar el conocimiento del asunto porque carecen, en efecto, de poder jurisdiccional sobre el litigio (art. 21 LOPJ y art. 38 LEC). Afirman, en efecto, que los tribunales españoles no pueden juzgar a un Estado extranjero, Cuba, ya que, en realidad, dichos órganos jurisdiccionales deben decidir sobre la legalidad o ilegalidad de un acto soberano como es una expropiación de unos terrenos llevada a cabo por un Estado extranjero, Cuba, en el territorio de otro país. Y como la expropiación constituye siempre un acto jure imperium, un acto soberano, en esta ocasión, del Estado cubano, resulta que el Estado español no puede juzgarlo. Es la inmunidad de jurisdicción. Según esta noción, explican A.-L. CaLvo CaravaCA / J. CARrascosa GonzÁlez, "los órganos jurisdiccionales de un Estado no pueden conocer de un litigio en el que sean demandados por un particular, un Estado extranjero o alguno de sus órganos, así como otros entes internacionales que gozan de tal inmunidad"5. En tal caso, los tribunales de un Estado, se dice, carecen de "jurisdicción" para conocer del asunto. Por ello, esta inmunidad no es una excepción a la "competencia judicial internacional" de los tribunales de un Estado. Es una excepción a la "jurisdicción" de dichos tribunales, que carecen de poder jurisdiccional para conocer del asunto, ya que éste versa sobre un objeto sustraído a la acción de los tribunales de justicia.

5. Consideran los demandados, en segundo lugar, y por si no fuera suficiente el argumento anterior, que los tribunales españoles carecen de competencia internacional para conocer de esta reclamación por enriquecimiento injusto, ya que la acción ejercitada es una acción real que recae sobre inmuebles sitos en otro país, Cuba. La base jurídica de este planteamiento es clara: los jueces españoles no disponen de un foro de competencia internacional para decidir litigios en los que se ha ejercitado una acción real relativa a inmuebles situados en el territorio de otros Estados. Eso sería invadir la soberanía territorial de otro Estado, pues los tribunales de un Estado son los únicos que pueden decidir sobre litigios relativos a derechos reales que se refieren a inmuebles sitos en el territorio de tal Estado (vid. art. 24.1 RB I-bis y art. 22.1 LOPJ ambos por analogía).

6. El Auto JPI Palma Mallorca 2 septiembre 2019 da toda la razón a los demandados ${ }^{6}$.

En primer término, estima el juzgador de primera instancia que el actor había ejercitado una acción real ante los tribunales españoles. En consecuencia, estimó que no era internacionalmente com-

\footnotetext{
5 A.-L. Calvo Caravaca / J. Carrascosa González, Derecho internacional privado, vol. I, $18^{a}$ edición, Ed.Comares, Granada, 2018, pp. 1280-1282; A.-L. Calvo Caravaca / J. CARrascosa GonzÁlez (Directores), Derecho internacional privado, vol. II, $18^{a}$ edición, Comares, Granada, 2018, pp. 117-119.

${ }^{6}$ Auto JPI Palma Mallorca 2 septiembre 2019 [ECLI:ES:JPI:2019:6A].
} 
petente al respecto al corresponder dicha materia a la competencia exclusiva de los tribunales cubanos: bienes inmuebles en Cuba, competencia internacional exclusiva de los tribunales cubanos. De ese modo, evitaba el juzgado entrar en el fondo de la cuestión y pronunciarse sobre si había habido o no "enriquecimiento injusto" que era la causa de pedir del actor.

En segundo lugar, el juzgado precisó que Cuba es un Estado soberano y que gozaba de inmunidad de jurisdicción. Por ello, también decidió no entrar en el fondo del asunto: los tribunales españoles no pueden juzgar a un Estado extranjero, Cuba, que opera jure imperium, como Estado que ejercita sus competencias soberanas sobre bienes situados en su propio territorio.

7. En consecuencia, el juzgado mallorquín afirmó que los tribunales españoles (i) carecían de jurisdicción sobre el asunto ya que el Estado cubano no puede ser demandado en España porque goza de inmunidad de jurisdicción y (ii) tampoco disponían los tribunales españoles, a fortiori, de competencia internacional para conocer del litigio ya que la acción ejercitada era una acción real sobre bienes inmuebles situados en el extranjero. Por ello, el juzgado no entró en el fondo del asunto. El juzgado mallorquín acoge ambos argumentos de los demandados y estima la declinatoria de competencia internacional y la declinatoria de jurisdicción.

\section{El auto de la Audiencia Provincial de las Islas Baleares de 18 marzo 2020.}

8. Los dos argumentos empleados por el Juzgado de primera instancia son, en buena dogmática jurídica, débiles y parecen poco meditados. Por ello, la estimación de la excepción declinatoria de jurisdicción y de competencia internacional por tal juzgado fue objeto del casi siempre inevitable recurso de apelación ante la Audiencia Provincial de Mallorca. El Auto de AP Baleares de 18 marzo 2020 resuelve la apelación contra la estimación de la declinatoria e imprime un giro radical de 180 grados al estado jurídico de la cuestión?

9. En primer lugar, por lo que se refiere a la inmunidad de jurisdicción, debe recordarse que los tribunales españoles deben apreciar de oficio la existencia de la misma, tan pronto como sea advertida (art. 38 LEC). Lo harán con audiencia de las partes y del Ministerio Fiscal. No es preciso que el Estado cubano alegue la inmunidad de jurisdicción. No obstante, también éste puede hacerla valer, mediante declinatoria, ante el tribunal (arts. 36.2 y 39 LEC), lo que, todo hay que decirlo, no sucedió. Ahora bien, -y aquí radica el quid de la cuestión, como resulta evidente-, un pequeño detalle aflora inexorablemente como las amapolas en primavera. En efecto, en este litigio, la acción se ejercita contra una empresa privada (Hoteles Meliá), cuya sede social se halla en España y que ha explotado y explota todavía hoy los terrenos confiscados y situados en Cuba. No se demanda, en ningún momento, al Estado cubano. Cuba no es el demandado en este proceso civil que se desarrolla ante los tribunales mallorquines. Qué cosas tiene el Derecho Procesal.

10. El art. 2 de la Ley Orgánica 16/2015, de 27 de octubre, sobre privilegios e inmunidades de los Estados extranjeros, las Organizaciones Internacionales con sede u oficina en España y las Conferencias y Reuniones internacionales celebradas en España indica que "a los efectos de la presente Ley Orgánica, se entiende por: a) Inmunidad de jurisdicción: prerrogativa de un Estado, organización o persona de no ser demandado ni enjuiciado por los órganos jurisdiccionales de otro Estado"8. Se puede invocar la inmunidad de jurisdicción sólo cuando el Estado extranjero sea "demandado" en un proceso ante tribunales españoles. En el presente supuesto, por tanto, el juzgador mallorquín no puede estimar la existencia de una inmunidad de jurisdicción del demando porque el demandado no es el Estado cubano.

\footnotetext{
${ }^{7}$ Auto AP Baleares 18 marzo 2020 [ECLI: ES:APIB:2020:37A].

${ }^{8}$ Ley Orgánica 16/2015, de 27 de octubre, sobre privilegios e inmunidades de los Estados extranjeros, las organizaciones internacionales con sede u oficina en España y las conferencias y reuniones internacionales celebradas en España (BOE núm. 258 de 28 octubre 2015 ).
} 
otra vez. La utilización del participio "enjuiciado" por el precepto antes citado no cambia ese enfoque. Se refiere este término a una posible reclamación en el orden jurisdiccional penal contra un Estado extranjero visto que hoy día, en Derecho español, societas delinquere sic potest. Además, si el Estado cubano no ha sido demandado ante los tribunales españoles, lógicamente no habrá sido notificado y no podría renunciar a su inmunidad de jurisdicción, que es su derecho también. En suma: la inmunidad de jurisdicción sólo se puede apreciar si el demandado es un Estado y no se puede apreciar si el Estado no ha sido demandado ante tribunales españoles, como se deduce con transparente claridad del aludido art. 36 LEC. En este caso, por tanto, el tribunal mallorquín no debió apreciar la inmunidad de jurisdicción del Estado cubano porque éste nunca fue demandado en el proceso que se abrió en España. Son, otra vez, esas cosas del Derecho procesal, En suma, este epatante error del juzgado es corregido por el auto de la Audiencia Provincial de las Islas Baleares que, con los argumentos vertidos, indica de modo lúcido que los tribunales españoles disponen de jurisdicción para decidir este caso y que la inmunidad de jurisdicción no opera en el mismo, al no ser el Estado cubano demandado ante los tribunales españoles. Por otro lado, es sabido que esta excepción debe interpretarse de modo restrictivo y, como demuestra B. Hess, extenderla más allá de los casos específicamente contemplados por la Ley y que se refieren a actos que, indubitadamente, se califican como acta jure imperii, es inapropiado?

11. En segundo lugar, en cuanto al carácter real de la acción y a la incompetencia internacional de los tribunales españoles para juzgar un caso que se refiere a la propiedad de unos inmuebles sitos en Cuba (= excepción declinatoria de competencia internacional), debe arrancarse del art. 24 RB I-bis ${ }^{10}$. Este precepto, como es sabido, no protege las competencias exclusivas de Estados no miembros de la UE, como Cuba. El planteamiento del juzgado mallorquín es comprensible: dicho juzgado no deseaba juzgar la legalidad o ilegalidad de una expropiación llevada a cabo por el Gobierno de Cuba sobre bienes situados en Cuba. Sin embargo, su planteamiento resulta jurídicamente infundado. La acción ejercitada por los propietarios originarios de los inmuebles sitos en Cuba presentaba una naturaleza claramente extracontractual. Desean percibir una indemnización derivada de un enriquecimiento injusto, no persiguen que se les devuelva la propiedad confiscada en Cuba. No pretenden los actores que un juzgado español declare que los terrenos confiscados en playa esmeralda les pertenecen. La acción de enriquecimiento injusto ejercitada ante los tribunales mallorquines posee un fundamento puramente recuperatorio tras haberse acreditado unos daños. Nada que ver con una acción real. Es una acción extracontractual, una acción por daños. Visto que no es una acción real sobre bienes inmuebles situados en el extranjero, los tribunales españoles son perfectamente competentes para conocer de la misma. Concurre un clarísimo foro de competencia internacional, pues el domicilio del demandado se encuentra en España (art. 4 RB I-bis). La Audiencia Provincial de Palma de Mallorca así lo indica. Los tribunales españoles no sólo son internacionalmente competentes para conocer del litigio suscitado, sino que están obligados a conocer del mismo. Los tribunales baleares no pueden recurrir a un ersatz del anglosajón forum non conveniens y afirmar que, como la expropiación ocurrió en Cuba y los bienes inmuebles están en Cuba, es mejor, y más conveniente que sean los tribunales cubanos los que decidan sobre la indemnización derivada de un posible enriquecimiento injusto de la empresa hotelera española. El sistema europeo de competencia judicial internacional es un sistema de base legal, puramente continental, en el que, si el foro concurre, el juez está obligado a conocer del litigio sean cuales fueren las conexiones del asunto con otros países

12. Como consecuencia de lo anterior, todas las cavilaciones, pensamientos, debates y dudas que surgen en torno a la cuestión de saber si los tribunales españoles pueden conocer de los litigios suscitados por el ejercicio de una acción real sobre bienes inmuebles situados en otros países, son, en

\footnotetext{
${ }^{9}$ B. Hess, "Abgrenzung der acta iure gestionis und acta iure imperii: Der BGH verfehlt die völkerrechtliche Dimension der Staatenimmunität", IPRax, 2018-4, pp. 351-355.

${ }^{10}$ Reglamento (UE) n. 1215/2012 del Parlamento Europeo y del Consejo de 12 de diciembre de 2012 relativo a la competencia judicial, el reconocimiento y la ejecución de resoluciones judiciales en materia civil y mercantil (refundición) (DOUE L 351 de 20 diciembre 2012), conocido como Reglamento Bruselas I-bis.
} 
relación con este caso, improcedentes. En todo caso, valga recordar, siempre con mesura y prudencia, que en el marco del Reglamento Bruselas I-bis, un tribunal español puede conocer de litigios que pertenecen a la competencia judicial exclusiva de terceros Estados no participantes en el Reglamento Bruselas I-bis, si bien la cuestión es controvertida en la doctrina especializada. Los tribunales de un Estado miembro deben conocer del asunto si concurre, según el Reglamento Bruselas I-bis, algún foro de competencia judicial, como la sumisión de las partes o el domicilio del demandado en un Estado miembro. Ésta es la tesis oficial recogida en el Informe oficial P. JENARD / G. MöLler de 1990, Informe Almeyda / Desantes / Jenard de 1989 y en el Informe Pocar sobre el Convenio de Lugano II, núm. $93^{11}$. En efecto, el Reglamento Bruselas I-bis no contiene una "regla negativa de competencia judicial internacional" que impida a los tribunales de los Estados miembros conocer de estos casos por la razón de que el Reglamento, naturalmente, como recuerda C. THOLE, no protege las competencias judiciales exclusivas de terceros Estados ${ }^{12}$. La teoría evita una denegación de Justicia en la UE: nada asegura que la resolución que pudieran dictar en estas materias los tribunales de un tercer Estado no miembro vaya a ser reconocida en los Estados miembros. Debe también destacarse que el TJUE ha seguido esta tesis, pues ha admitido que un tribunal de un Estado miembro puede declararse competente en relación con un litigio relativo a un derecho real sobre un inmueble situado, de facto, en un territorio que no está bajo la soberanía de un Estado miembro (STJCE 28 abril 2009, C-420/07, Apostolides, FD 35-36) ${ }^{13}$. En el fondo, para esta teoría, el hecho de que exista una competencia exclusiva en favor de tribunales de terceros Estados es un hecho completamente irrelevante en el sistema de competencia judicial internacional del Reglamento Bruselas I-bis. Dice así el Informe Jenard / Möller anejo al Convenio de Lugano de 1988, antes citado: "Article 16 (1) applies only if the property is situated in the territory of a Contracting State. The text is sufficiently explicit on this point. If the property is situated in the territory of a third State, the other provisions of the Convention apply, e.g. Article 2 if the defendant is domiciled in the territory of a Contracting State, and Article 4 if he is domiciled in the territory of a third State, etc.".

13. Queda por decidir una cuestión que no es baladí: la eficiencia de una litigación ante tribunales españoles en casos como éste. Pues bien, puede destacarse, con S. DNES, que visto que la sentencia que pueda dictarse por tribunales españoles puede ejecutarse sin problemas en España sobre bienes que el demandado tiene en España, la litigación basada en el actor seguir es perfectamente eficiente ${ }^{14}$. Como ha explicado J. CARrascosa GonzÁlez, este foro sólo alcanza un sentido eficiente si recupera su verdadero y prístino significado: se debe litigar donde están los bienes sobre los que puede recaer la actividad ejecutiva, que normalmente, -aunque no siempre-, se hallan situados en el lugar del domicilio del demandado ${ }^{15}$. Qué más da que la expropiación tuviera lugar sobre bienes sitos en Cuba si no se solicita ninguna actividad de ejecución en dicho país, sino en España.

\section{Efectos jurídicos en España de una expropiación llevada a cabo en país extranjero.}

14. El auténtico punctum dolens de este litigio radica en saber si, como cuestión previa a la cuestión principal del enriquecimiento injusto, un tribunal español puede decidir en relación con la legalidad o ilegalidad de una expropiación llevada a cabo por un Estado extranjero sobre bienes inmuebles situados en su territorio.

\footnotetext{
${ }^{11}$ DOUE 13 diciembre 2009.

${ }^{12}$ C. Thole, "Die Reichweite des Art. 22 Nr. 2 EuGVVO bei Rechtsstreitigkeiten über Organbeschlüsse", IPRax, 2011-VI, pp. 541-547.

${ }_{13}$ STJCE 28 abril 2009, C-420/07, Meletis Apostolides vs. David Charles Orams, Linda Elizabeth Orams, Recopilación, 2009, p. I-357 [ECLI:EU:C:2009:271].

14 S. Dnes, "Promoting efficient litigation?", en P. Beaumont et al., Cross-border litigation in Europe, Oxford, Hart, 2017, pp. 463-473.

15 J. Carrascosa GonzÁlez, "Foro del domicilio del demandado y Reglamento Bruselas I-is 1215/2012. Análisis crítico de la regla actor sequitur forum rei", Cuadernos de Derecho transnacional (CDT), 2019, vol. 11, n. 1, pp. 112-138.
} 
15. Toda expropiación tiene lugar en virtud y en aplicación del Derecho de intervención del Estado expropiador, como recuerda I. GUARDANS I CAMBÓ ${ }^{16}$. La expropiación se lleva a cabo por órganos de un Estado que desarrollan funciones propias de ese Estado (jure imperium). Estos actos de expropiación se rigen por normas de Derecho Público de dicho Estado expropiador. Este dato no está en discusión ante los tribunales españoles. Ahora bien, ello no impide que los tribunales españoles puedan decidir el caso que aquí se comenta.

16. Constituye un error, y no leve, afirmar que, en este litigio objeto de las decisiones judiciales mallorquinas de referencia, la Audiencia Provincial de las Islas Baleares ha subrayado que los tribunales españoles pueden juzgar, en un proceso declarativo, si la expropiación de ciertos bienes inmuebles sitos en país extranjero y llevada a cabo por un Estado extranjero, ha sido ajustada a la legalidad o no. Es también un error afirmar que la Audiencia Provincial de las Islas Baleares, en su auto citado, permite que los tribunales españoles decidan un litigio cuyo objeto es la propiedad de unos bienes inmuebles que han sido expropiados por un Estado extranjero. La Audiencia Provincial de las Islas Baleares jamás ha afirmado tales cosas. Eso es pura apariencia y sostener eso significa que manca finezza en el jurista. Cuánto se puede aprender del concepto de "objeto del proceso". Porque el objeto del proceso, en este caso, no es la propiedad de los terrenos sitos en Playa Esmeralda ni tampoco es la legalidad o no de la expropiación llevada a cabo por el gobierno cubano. El objeto del proceso es una simple reclamación de indemnización pecuniaria por daños derivados de un enriquecimiento injusto: una empresa española obtiene ventajas económicas a costa del correlativo empobrecimiento de una familia española.

17. La óptica correcta para abordar este caso es la perspectiva propia del "reconocimiento en España de las decisiones de expropiación acordadas por Estados extranjeros". Los problemas que plantean estos procesos de transferencia obligatoria de propiedad en favor del Estado no constituyen problemas de "Ley aplicable" a la expropiación. Son problemas de "validez extraterritorial" de las decisiones extranjeras de expropiación, como pusiera de relieve el ya clásico estudio de P. MAYER ${ }^{17}$. Es decir, se trata de especificar los efectos jurídicos que las medidas expropiatorias adoptadas por autoridades extranjeras producen en el ordenamiento jurídico español. En consecuencia, cuando un tribunal español debe resolver una cuestión jurídica y para ello debe valorar los efectos legales en España de una expropiación llevada a cabo por un Estado extranjero, no vulnera la competencia exclusiva de los tribunales del Estado extranjero para decidir cuestiones relativas a derechos reales inmobiliarios (art. 24.1 RB I-bis y art. 22.1 LOPJ a contrario sensu). En tal supuesto, los jueces españoles, simplemente, deciden si procede conceder efectos legales o no conceder efectos legales en España a un acto soberano que tuvo lugar en otro país y ordenado y ejecutado por un Estado extranjero.

18. Las acciones ejercitadas ante tribunales españoles y en las que se reclama una indemnización por daños y perjuicios como consecuencia de una expropiación ilegal de unos inmuebles sitos en Cuba y llevada a cabo por el Gobierno revolucionario cubano son "acciones extracontractuales". El tribunal español es competente si el domicilio del demandado se encuentra en España (art. 4 RB I-bis), lo que en el caso de especie resulta indiscutible. Así las cosas, el tribunal español debe decidir, previamente al fondo del asunto, sobre el reconocimiento en España de los efectos jurídicos de los actos expropiatorios verificados en Cuba, esto es, sobre el ajuste a Derecho de tales actos expropiatorios. En dicho proceso, aunque es claro que el Derecho cubano rige la expropiación, los efectos jurídicos de la misma en España

${ }^{16}$ I. Guardans I Cambó, Contrato internacional y Derecho imperativo extranjero. De la jurisprudencia comparada al Convenio de Roma de 19-6-1980, Pamplona, 1992, pp. 230-249.

${ }_{17} \mathrm{P}$. MAYER, La distinction entre règles et décisions et le droit international privé, Bibliothèque de droit international privé, vol. XVII, Paris, Dalloz, 1973, esp. n. 159. La tesis ya fue originariamente avanzada por F. Munch, "Les effets d'une nationalisation á l'étranger”, RCADI, 1959, vol.98, pp. 411-504. Vid. también P. MAYER / V. Heuzé / B. Remy, Droit international privé, $12^{\mathrm{a}}$ ed., Paris, LGDJ, Lextenso, 2019, pp. 434-439. Se supera así el tradicional enfoque de la doctrina italiana sobre el particular, enrocada en valorar la cuestión desde el ángulo de la aplicación extraterritorial de las leyes de expropiación de otros Estados: G. BiscottinI, "L'efficacité des actes administratifs étrangers", RCADI, 1961, vol.104, pp. 635-695; G. Fedozzi, "De l'efficacité extraterritoriale des lois et des actes de droit public", RCADI, 1929, vol.27, pp. 141-242. 
pueden denegarse si los tribunales españoles consideran que la expropiación vulnera el orden público internacional español.

19. En un caso semejante al que aquí se comenta, el caso de la expropiación de la marca Havana Club, la STS 30 diciembre 2010, muy bien analizada por A. Hernández Rodríguez / C. MaCho Gómez, entendió que la nacionalización de dicha marca llevada a cabo en 1960 por el Estado cubano infringió el orden público internacional español y no le otorgó efectos legales en España ${ }^{18}$. En ese supuesto, cabe recordar que los derechos de la marca de ron "Havana Club" pertenecen, en Cuba y otros países, empresa mixta cubano-francesa (Cubaexport y Pernod Ricard), mientras que en USA, dicha marca pertenece a Bacardí USA, una empresa norteamericana que comercializa en dicho país un ron con la marca "Havana Club". Esta situación se produce porque la marca "Havana Club" fue creada por la familia española Arechabala en 1935, familia que posteriormente vendió sus derechos sobre dicha marca a la empresa Bacardí. El Gobierno castrista expropió la marca "Havana Club" en 1960 pero dicha expropiación no fue reconocida en USA, de modo que, en Cuba, la marca pertenece a unos titulares, -la empresa mixta cubano-francesa Cubaexport y Pernod Ricard-, mientras que la misma marca pertenece a la empresa "Bacardí USA" en los Estados Unidos de América, empresa que produce ron en fábricas que posee en Puerto Rico ${ }^{19}$. Debido al embargo comercial de Cuba y al hecho de que "Havana Club" es una marca que pertenece, en los Estados Unidos de América, a Bacardí USA, los titulares de la marca en Cuba no pueden exportar su ron a los Estados Unidos de América. Un ron, dos países y dos marcas diferentes, pero con igual denominación. La STS 30 diciembre 2010 entendió que la nacionalización de la marca llevada a cabo en 1960 por el Estado cubano infringió el orden público internacional español, lo que impide que los sucesivos adquirentes de la marca puedan ser considerados "propietarios" de la misma ${ }^{20}$. En efecto, estimaron los tribunales españoles que la expropiación de la marca no se ajustó a procedimiento legal alguno, que los expropiados no fueron escuchados y que jamás recibieron indemnización alguna.

20. En consecuencia, en el caso "playa esmeralda" no se vulnera la competencia internacional exclusiva de los tribunales cubanos para decidir, en un proceso declarativo, sobre la titularidad y propiedad de un bien expropiado. Se trata, sencillamente, de juzgar sobre los efectos legales en España de una expropiación que se ha producido en el extranjero.

21. Es cierto que el Derecho internacional privado español carece de normas específicas relativas a los efectos en España de medidas expropiatorias acordadas por autoridades extranjeras. Para integrar la laguna legal y decidir si un acto de expropiación extranjero surte efectos legales en España, deben controlarse dos extremos.

22. En primer lugar, debe explorarse y afirmarse la competencia internacional del Estado que dicta el acto público expropiatorio. En general, puede afirmarse que el Derecho internacional público proporciona criterios generales válidos para delimitar del ámbito en el que cada Estado puede ejercer sus competencias soberanas. Se trata de delimitar el ámbito territorial en el que los Estados pueden ejercitar y ejecutar actos de fuerza o coacción (Sent.TPJI 7 septiembre 1927, Lotus) ${ }^{21}$. Puede decirse, así, que, en principio, cada Estado posee competencia para dictar actos públicos de nacionalización o expropiación

${ }^{18}$ A. Hernández Rodríguez / C. MAcho Gómez, "Eficacia internacional de las nacionalizaciones sobre las marcas de empresa: el asunto «Havana Club» ante los tribunales españoles", Cuadernos de Derecho Transnacional CDT, 2012, pp. 159-176. Vid. también J. CARRASCOSA GonZÁlez, "¡Exprópiese otra vez y más y más! España, Cuba y Estados Unidos de América: ¿hace un ron Havana Club?", http://accursio.com/blog/?p=1123, (14 junio 2020). En relación con las expropiaciones de derechos incorporales resulta muy ortodoxa la aproximación de A. QuiÑones EsCÁMEZ, "Problemas jurídico-internacionales relativos a la propiedad de la marca "Dry Sack" y otras surgidas a raíz de la expropiación del holding Rumasa", RJ La Ley, núm.980, 13 julio 1984, pág.2-4; ID., Eficacia internacional de las nacionalizaciones. Nombre comercial y marcas, Ed.Montecorvo, Madrid, 1988.

${ }_{19}$ Diario El País, 31 marzo 2009. Vid. J. Carrascosa GonzÁlez, "Derechos reales" en A.-L. Calvo Caravaca / J. Carrascosa GonzÁLEZ, Derecho internacional privado, vol. II, $18^{\text {a }}$ edición, Ed.Comares, Granada, 2018, pp. 1221-1227.

${ }^{20}$ STS 30 diciembre 2010 [ECLI:ES:TS:2010:7666].

${ }^{21}$ Sentencia del TPJI de 7 septiembre 1927, Lotus, cuyo texto puede leerse en: http://www.dipublico.org/10984/s-s-lotus1927-corte-permanente-de-justicia-internacional-ser-a-no-10/. 
en relación a bienes que, en el momento de la expropiación, se hallan en su territorio. Es el "principio de territorialidad positivo" o de "soberanía económica del Estado" al que se refiere A.S. El Kocheri ${ }^{22}$. En el presente supuesto, no cabe albergar duda alguna sobre la competencia territorial del Estado cubano para expropiar unos terrenos situados en la isla de Cuba. Todo Estado está legitimado por el Derecho internacional para expropiar los bienes que se encuentran situados en su territorio (sentencia de la cour de cassation francesa de 20 febrero 1979, SMC ${ }^{23}$. Así, el Gobierno de la República Española declaró, el 26 noviembre 1931, a SAR D. Alfonso XIII, "culpable de alta traición" y declaró incautado en favor del Estado español "todos los bienes, derechos y acciones de su propiedad que se encuentren en el territorio nacional". Y no influye el hecho de que, tras la expropiación, el bien sea trasladado al extranjero.

23. En segundo lugar, debe valorarse la conformidad del acto público expropiatorio con el orden público internacional español. La intrincada y siempre incómoda cuestión de la legalidad en España de una expropiación llevada a cabo por Cuba en su territorio debe juzgarse, destaca TH. HeFTI, tanto con arreglo al Derecho internacional general como con arreglo a los principios que conforman el orden público internacional del Estado donde se desea hacer valer la transferencia de la propiedad que supone la expropiación, en este caso, el orden público internacional español ${ }^{24}$.

24. En lo que se refiere a la conformidad del acto expropiatorio con el orden público internacional español, cabe recordar, de nuevo, que el acto público extranjero de expropiación se lleva a cabo, siempre, con arreglo a la Ley del Estado expropiador. El hecho de que los bienes sean propiedad de extranjeros o el hecho de que la sociedad a intervenir tenga bienes en otros países, no cambia dicho principio. Ahora bien, ello no significa que toda expropiación llevada a cabo por Estados extranjeros sobre bienes sujetos a su "control fáctico" o a su "competencia territorial" despliegue, sin más, efectos en España. El acto expropiatorio extranjero no debe producir efectos contrarios al orden público internacional español. Los principios que componen el orden público internacional español en el sector de la privación forzosa de la propiedad son los que siguen (vid. arts. 33, 38 y $128 \mathrm{CE}$ ): (a) Existencia una causa de "interés general" en la expropiación; (b) Indemnización justa al expropiado. La STS 30 diciembre 2010 entendió que la nacionalización de la marca llevada a cabo en 1960 por el Estado cubano infringió el orden público internacional español, porque se prescindió de todo proceso y procedimiento y no se proporcionó compensación alguna a los expropiados, como antes se ha indicado; (c) Procedimiento regular de expropiación que permita la defensa jurídica del expropiado; (d) Ausencia de discriminación en la expropiación; (e) Carácter no sancionatorio de la expropiación: las expropiaciones llevadas a cabo como "represalia" o sanción" contra un sujeto presentan carácter penal y vulneran el orden público internacional. Ejemplo: la jurisprudencia británica rechazó dar efectos en Inglaterra a la expropiación de todos los valores y bienes del ex-Rey de España SAR D. Alfonso XIII decretada por el Gobierno de la República española, que consideró al ex-monarca "culpable de alta traición" el 26 noviembre $1931^{25}$

25. Por otra parte, y desde el punto de vista del Derecho internacional público, es claro que cada Estado dispone de un derecho a "controlar" los recursos naturales sitos en su territorio y las actividades económicas desarrolladas en el mismo. Este principio de "soberanía permanente de los Estados sobre sus recursos naturales" constituye un elemento importante del Nuevo Orden Económico Internacional. Desde el prisma del Derecho internacional público, la expropiación o similar acordada por el Estado será ajustada al Derecho Internacional, que en este punto, es una regulación consuetudinaria, si concurren estas circunstancias: (a) Existencia de motivos de utilidad pública o social, seguridad o interés nacional que amparen la medida; (b) Procedimiento llevado a cabo sin discriminación, en particular, si

${ }^{22}$ A.S. El KoCHERI, "Les nationalisations dans les pays du Tiers monde devant le juge occidental”, RCDIP, 1967, vol.LVI, pp. 249-275.

${ }^{23}$ Sent. Cour de Cassation de Francia 20 febrero 1979, SMC, RCDIP, 1979, p. 803, nota H. BatiFfol.

${ }^{24}$ Тн. Hefті, La protection de la propriété étrangère en droit international public, Neuchâtel,Zürich, Schulthess Polygraphischer Verlag, 1989, esp. pp. 29-33.

${ }^{25}$ Caso Banco de Vizcaya vs. D. Alfonso de Borbón y Austria, 1935 [1935 1 KB 140]. 
no se dirige exclusivamente contra extranjeros sólo por el hecho de serlo; (c) Compensación "inmediata, adecuada en valor y efectiva" en favor del perjudicado por la medida ("fórmula Hull"). La falta de concurrencia de alguno de estos requisitos podría derivar en una responsabilidad que puede exigirse, por un Estado a otro Estado, con arreglo a los medios y normas propias del Derecho internacional público. Puede también derivar en un ejercicio de la protección diplomática por parte del Estado cuya nacionalidad ostenta en sujeto que ha visto cómo otro Estado expropiaba sus propiedades sin respetar el Derecho Internacional Público.

\section{Reflexiones finales}

26. En primer lugar, puede dar la impresión de que el juzgado de primera instancia de Palma de Mallorca cometió errores jurídicos de gran envergadura y que adoptó una decisión contra legem. Es indudable que así fue y que, por tanto, la corrección efectuada por la Audiencia Provincial de las Islas Baleares, "suaviter in modo, fortiter in re" bien hecha estuvo. Sin embargo, ello no significa que el juzgado de primera instancia de Palma de Mallorca no supiera lo que hacía. Tenía poderosas razones para no querer decidir sobre el fondo del litigio. En efecto, dicho juzgado no quiso situarse en una posición geopolítica inadecuada que le obligara a pronunciarse sobre la legalidad de la expropiación realizada por el Estado cubano. Es ésa una cuestión extremadamente delicada que aparece conectada con la soberanía de cada Estado. Tampoco al Estado español le agradaría, por ejemplo, que los tribunales polacos, británicos o cubanos afirmasen que la expropiación de Rumasa de fecha 23 febrero 1983 y llevada a cabo por el gobierno de España, fue ilegal e injusta ${ }^{26}$. El juzgado mallorquín no quiso entrar en el asunto y, con tal objetivo, utilizó las dos estrategias reseñadas: la calificación de la acción como "acción real sobre bienes inmuebles" y la inmunidad de jurisdicción del Estado cubano, probablemente sugeridas por la contestación a la demanda. La argumentación es errónea y el resultado es injusto, por lo que fue debidamente corregida por la Audiencia Provincial. Sin embargo, la posición del juzgado no es irracional, sino perfectamente comprensible. El juzgado mallorquín actuó como lo habría hecho un tribunal norteamericano, pues en los Estados unidos de América se sigue la teoría del "acto de Estado" ("Act of State”). Según la misma, explica P. Herzog, los tribunales de un Estado no pueden pronunciarse sobre la validez o invalidez de un acto de un Gobierno de otro Estado dictado en el ejercicio de las competencias soberanas de ese otro Estado en su territorio ${ }^{27}$. La teoría surgió al socaire de un caso que se produjo cuando tuvo lugar la revolución venezolana de 1892 y el general José Manuel "Mocho" Hernández expulsó al gobierno de Venezuela y tomó el control de Ciudad Bolívar. El ciudadano norteamericano Mr Underhill vivía en dicha ciudad y gestionaba el sistema de abastecimiento de agua de la misma. Mr Underhill fue obligado, contra su voluntad, a continuar el abastecimiento de agua a la ciudad y a realizar ciertas obras relacionadas con dicho abastecimiento. Tras muchas resistencias del gobierno venezolano, se permitió a Underhill que regresase a los Estados Unidos, ante cuyos tribunales ejerció una acción para reclamar los daños de su retención en Venezuela. El tribunal de Nueva York determinó que el general Hernández representaba al gobierno venezolano y que un tribunal norteamericano no podía juzgar los actos de un gobierno extranjero ocurridos en territorio de este otro país (= "every sovereign state is bound to respect the independence of every other sovereign state, and the courts of one country will not sit in judgment on the acts of the government of another, done within its own territory"). Esta teoría, típicamente territorialista, opera en los Estados Unidos de América y los jueces de dicho Estado la aplican regularmente. No está admitida, sin embargo, por normas convencionales o consuetudinarias del Derecho Internacional Público. Los perjudicados por los actos llevados a cabo por Gobiernos extranjeros en sus territorios deben litigar ante los tribunales de

${ }^{26}$ I. Seidl-Hohenveldern, "The Rumasa Decision of the House of Lords and the Doctrine of Severance of Corporations", en B. Cheng / E.D. Brown (eds.): Contemporary Problems of International Law. Essays in honour C.Scwarzenberger, Londres, 1988, pp. 262-274, explica que, por fortuna para el gobierno español, la expropiación referida fue considerada plenamente válida por los tribunales británicos, al estimar éstos que había sido realizada por un "Estado hermano" en la Comunidad europea sobre una base legal y axiological que podia ser compartida por el Reino Unido. Eran otros tiempos, es cierto.

${ }^{27}$ P. Herzog, "La théorie de l'Act of State dans le droit des Etats-Unis", RCDIP, 1982, pp. 617-646. Vid. Sent. TS USA Underhill vs. Fernández 168 US 250 (1897). 
dichos Estados o instar negociaciones diplomáticas entre los Estados Unidos y los otros Estados. No están legitimados para litigar contra los Estados extranjeros, por estos actos, ante los tribunales norteamericanos. La doctrina del Act Of State no opera, sin embargo, en el caso de actos del Poder Público extranjero que suponen vulneraciones flagrantes de "reglas importantes del Derecho internacional". Es la "doctrina Berstein": un ciudadano norteamericano fue desposeído de sus bienes en Alemania por el Gobierno nazi y los bienes fueron entregados a un administrador nazi. El Sr. Berstein solicitó una indemnización ante los tribunales norteamericanos. En este caso, el Gobierno norteamericano puede indicar al tribunal de su país que no existe ninguna razón que pueda enturbiar las relaciones internacionales y diplomáticas entre los Estados Unidos y el otro Estado extranjero si el caso es decidido por un tribunal norteamericano. De ese modo, queda desactivada la doctrina del Act of State. Pues bien, la teoría del Act Of State no tiene cabida en el Derecho internacional privado español. Por ello, un tribunal español, por ejemplo, puede valorar, en su caso, si la expropiación llevada a cabo en Cuba vulnera o no vulnera el orden público internacional español siempre que disponga de un foro de competencia judicial internacional a su favor. El auto JPI Palma Mallorca 2 septiembre 2019 incurre en numerosos errores, quién lo puede negar, pero no es ilógico. En realidad, el juzgado procedió a una aplicación silenciosa de la teoría del Act Of State. Lo que ocurre es que tal tesis no tiene cabida en Derecho español.

27. En segundo lugar, es claro que los tribunales españoles están facultados para decidir si los actos expropiatorios llevados a término por un Estado extranjero en relación con inmuebles situados en territorio de ese país extranjero pueden producir efectos jurídicos en España o no. Igual que los juzgados españoles están legitimados para decidir si un divorcio entre cónyuges rusos y pronunciado en Moscú por autoridades rusas puede producir efectos legales en España. En dicho contexto, es posible afirmar que una expropiación que no ha sido realizada conforme a un standard mínimo de justicia -indemnización a los perjudicados, audiencia a los mismos, un proceso justo, articulador y ajustado a la Ley-, no supera ese control de reconocimiento de su legalidad en España y no podrá hacerse valer en España. Ese tipo de expropiaciones son una expresión más del unilateralismo estatal. Y ya se sabe: el unilateralismo es egoísta, escribe F.J. Garcimartín Alférez ${ }^{28}$. Produce siempre resultados negativos y es ineficiente. Constituye una respuesta jurídica relativa, cortoplacista y de alcance limitado. Provoca también la respuesta de otros Estados a través de Blocking Statutes, normativas que tratan de inmovilizar y obstruir esas expropiaciones nacionalistas y egoístas. Las "expropiaciones agresivas" y las confiscaciones no circulan por el mundo, recuerda M. HERDEGEN ${ }^{29}$. Que es lo que, a todas luces, parece que podría ocurrir en este caso. Las expropiaciones agresivas constituyen una manifestación de la lucha geopolítica en el contexto globalizado del siglo XXI. Vuelven a la memoria las ponderadas, sensatas y brillantes palabras de GeRHARD Kegel: "todo está causalmente conectado con todo"30. La utilización, por parte de los Estados, de instrumentos jurídicos de Derecho internacional privado con el objetivo de ganar poder en el mundo coloca a los particulares en una situación legal difícil e incluso aleatoria, como muy bien precisó I. Guardans i Cambó ${ }^{31}$. En esta línea, escriben V. Ruiz Abou-Nigm / K. McCall-Smith / D. French, existen unos valores globales, tales como la eficiencia en la resolución de conflictos, la protección de la propiedad privada, evitar el enriquecimiento sin causa, luchar contra los comportamientos oportunistas, y otros en la misma línea, que evitarían la proliferación de estos Blocking Statutes, de estas normas que llevan a una "lucha normativa unilateral" que siempre resulta ineficiente para todos ${ }^{32}$.

${ }^{28}$ F.J. Garcimartín Alférez, “La racionalidad económica del DIPr.”, Cursos de Dcho.Internacional Vitoria-Gasteiz, 2001, Univ.País Vasco, pp. 88-154, esp. p. 115; M. Virgós Soriano / F. Garcimartín Alférez, "Estado de origen vs. Estado de destino", InDret Revista para el análisis del Derecho, www.indret.com, núm 251, 2004-4, noviembre 2004, pp. 1-20, esp. pp. 10-11. También en la misma línea, J. CARrascosa GonzÁlez, "La guerra transoceánica de Derecho internacional privado. Helms-Burton ataca de nuevo: una obra en siete actos", 5 mayo 2019, en http://accursio.com/blog/?p=883.

${ }^{29}$ M. Herdegen, Derecho económico internacional, Civitas, Madrid, 2005, pp. 89-91.

${ }^{30}$ G. Kegel, Internationales Privatrecht, München, Beck, 1987, p. 753.

31 I. Guardans I CAmbó, Contrato internacional y Derecho imperativo extranjero. De la jurisprudencia comparada al Convenio de Roma de 19-6-1980, Pamplona, 1992, pp. 230-249. En el mismo sentido, más recientemente, N. FerJani / V. Huet, "L'impact de la décision onusienne d'embargo sur l'exécution des contrats internationaux", JDI Clunet, 2010, pp. 737-760.

${ }^{32}$ V. Ruiz Abou-Nigm / K. McCall-Smith / D. French, Linkages and Boundaries in Private and Public International Law, Hart Publishing, 2018, pp. 11-13. 
28. En tercer lugar, debe subrayarse que el Derecho español no cuenta con una "Ley HelmsBurton"33. No existe una normativa española que disponga que los bienes transferidos por actos expropiatorios o confiscatorios llevados a cabo en Cuba nos nulos y que los perjudicados conservan el derecho a tales propiedades o deben ser indemnizados por los sujetos que se hayan aprovechado de tales actos de transferencia coactiva de la propiedad. Es más: el Derecho europeo se muestra muy reacio a estas normativas unilaterales que intervención, como puede apreciarse en el Reglamento (CE) 2271/96 del Consejo de 22 de noviembre de 1996 relativo a la protección contra los efectos de la aplicación extraterritorial de la legislación adoptada por un tercer país, y contra las acciones basadas en ella o derivadas de ella, elaborado para mitigar los efectos jurídicos de la Ley Helms-Burton en la UE ${ }^{34}$. Sin una "Ley Helms-Burton española" (= es decir, sin una normativa ordopolitica unilateral), el Derecho aplicable a los daños derivados de un posible enriquecimiento injusto que haya podido sufrir la persona cuyos bienes han sido expropiados, se debe precisar con arreglo a las normas españolas de conflicto de leyes. Todo parece indicar que tales normas, como se sugiere infra, conducen a la aplicación del Derecho cubano. Emplear normas de Derecho privado para lograr objetivos propios de la Geopolítica y de la política exterior es algo que puede hacerse, y de hecho, así se hace. Sin embargo, ello provoca una fuerte inestabilidad en las situaciones jurídicas que afectan a los particulares implicados, lo que hace que las soluciones pierdan eficiencia, tal y como apunta M. LIEBERKNECHTT ${ }^{35}$.

29. En cuarto lugar, no debe olvidarse que, en los casos de Derecho Privado, -y el Derecho internacional privado es un sector del Derecho Privado que regula situaciones jurídicas relativas a los particulares-, es el demandante el sujeto que decide, perfila y concreta el objeto del proceso. Ello significa que es el actor el que pide a los tribunales españoles lo que, concretamente, decide pedir y frente a quién lo quiere pedir. En este caso, el actor podía haber solicitado de los jueces españoles: (i) la declaración de propiedad a su favor de un bien inmueble sito en Cuba; (ii) la declaración de nulidad de la expropiación de un bien inmueble situado en Cuba llevada a cabo por el gobierno de Cuba; (iii) Una indemnización por los daños y perjuicios que la empresa hotelera española le ha producido al lucrarse con unos terrenos que le fueron arrebatados de modo presuntamente ilegal en Cuba. Optó por la tercera posibilidad e hizo muy bien, pues de ese modo, la competencia internacional de los tribunales españoles quedaba garantizada al tener el demandado su domicilio en España (art. 4. RB I-bis), se evitaba también la inmunidad de jurisdicción del Estado cubano, que no fue demandado en España y, finalmente eliminaba cualquier duda sobre la competencia de los tribunales españoles para decidir sobre la propiedad de un inmueble sito en el extranjero, pues nunca fue ésa la cuestión de fondo.

30. El resultado final al que conduce la desestimación de la excepción declinatoria de competencia internacional y de jurisdicción es que ahora el juzgado de primera instancia de Palma de Mallorca tendrá que valorar si la expropiación que realizó el gobierno cubano revolucionario de esos terrenos en Cuba fue "legal" o "ilegal" y si la cadena hotelera española se aprovechó de tal circunstancia para enriquecerse de modo injusto y sin causa, con el correspondiente empobrecimiento de la familia española originariamente propietaria de los terrenos de playa esmeralda. Se trata, sin duda, de un desafío de gran envergadura teórica y práctica. España no dispone, como sí los Estados Unidos de América, de una Ley similar a la Ley Helms-Burton ${ }^{36}$. No existe en Derecho español una disposición legal que indique que

33 J. CARrascosa GonzÁlez, "La guerra transoceánica de Derecho internacional privado. Helms-Burton ataca de nuevo: una obra en siete actos", en http://accursio.com/blog/?p=883, 5 mayo 2019; J. CARrASCOSA GonZÁLEz, "Geopolítica triangular y Derecho Internacional Privado. La Ley Helms Burton y la litigación internacional”, en Actas de las XXVIII Jornadas de la Asociación Española de Profesores de Derecho Internacional y Relaciones Internacionales. Nuevo Mundo, Nueva Europa. La redefinición de la Unión Europea en la Era del Brexit, Granada, 18-20 septiembre 2019, (en prensa).

${ }^{34}$ DOCE L 309 de 29 noviembre 1996.

${ }_{35}$ M. Lieberknecht, "Die Blocking-Verordnung: das IPR als Instrument der Außenpolitik", IPRax, 38, 6, 2018, pp. 573-579.

${ }^{36}$ Helms-Burton Act / Cuban Liberty and Democratic Solidarity (LIBERTAD) Act of 1995. Versión original en https:// www.treasury.gov/resource-center/sanctions/Documents/libertad.pdf. Versión en español en: https://web.archive.org/ web/20070730130013/http://www.icap.cu/pdf/ley\%20helms\%20burton.pdf. Vid. A.F. LowENFELD, “The Cuban Liberty and Democratic Solidarity (Libertad) Act: Congress and Cuba. The Helms-Burton Act”, AJIL, 1996, pp. 419-434; S.J. RuBIN, "Organization of American States, Inter-American Juridical Commitee Opinion Examining the U.S. Helms-Burton Act”, International 
nadie puede beneficiarse en España de las expropiaciones ilegales efectuadas en Cuba. ¿Qué dirán ahora los tribunales mallorquines? ¿Condenarán a la cadena hotelera española a pagar una indemnización a la familia española que fue propietaria de esas fincas cubanas llamadas "Ingenio Santa Lucía" y en las que se cultivaba caña de azúcar, por haberse lucrado tras una nacionalización contraria al Derecho internacional? La respuesta es un misterio envuelto en un enigma y escondido en un acertijo.

31. Dos extremos constituyen la clave de esta cuestión. En primer término, el ajuste o no de la expropiación de los terrenos sitos en playa esmeralda a los standards básicos de justicia internacionales y españoles, al orden público internacional español, cuyos puntos esenciales ya han sido destacados. En segundo lugar, la existencia de un auténtico enriquecimiento injusto del que se benefició el demandado. En relación con este asunto, cabe destacar que, si la expropiación se hubiera producido tras el día 11 enero 2009, la Ley aplicable al enriquecimiento injusto hubiera sido la Ley designada por el art. 4.2 RRII. Sin embargo, visto que la expropiación es muy anterior a esa fecha, y que la cadena hotelera comenzó a explotar dichos terrenos antes de dicho día, el Reglamento Roma II (Reglamento (CE) n.864/2007 del Parlamento Europeo y del Consejo de 11 de julio de 2007 relativo a la ley aplicable a las obligaciones extracontractuales, no es aplicable ${ }^{37}$. Es preciso volver la mirada atrás. La Ley aplicable a este presunto enriquecimiento injusto debería ser la Ley cubana. En efecto, para fijar dicha Ley aplicable es preciso concretar el momento en el que comienza el presunto enriquecimiento injusto. Si éste empezó antes de la vigente del actual art. 10.9.I CC (1974), el enriquecimiento producido entre dicho comienzo y la entrada en vigor del art. 10.9.I CC (1974) se rige por la Ley cubana, ya que puede sostenerse que desde 1889, año en el que entró en vigor el Código civil español, las obligaciones no contractuales se rigen por la Ley del país donde han ocurrido los hechos de los que tal responsabilidad deriva: Ley de Cuba. El art. 10 $\mathrm{CC}$ en su redacción originaria puede también servir de apoyo a esta solución, pues afirmaba que "[l]os bienes muebles están sujetos a la Ley de la nación del propietario; los bienes inmuebles, a las Leyes del país en que están sitos". Para los daños derivados de un enriquecimiento injusto verificados tras 1974, es aplicable el art. 10.9.III CC, empleado cuyo texto apunta claramente a la aplicación del Derecho cubano: "En el enriquecimiento sin causa se aplicará la ley en virtud de la cual se produjo la transferencia del valor patrimonial en favor del enriquecido". La transferencia de dicho valor se produce porque así lo dispone el Derecho cubano. En suma, el Reglamento Roma II no es aplicable para precisar la ley aplicable a este enriquecimiento injusto (arts. 30 y 31 RR-II), de modo que la cuestión debe ser resuelta mediante la aplicación del Código Civil español en su redacción originaria y en su redacción hoy vigente que data de 1974, lo que conduce a la aplicación de la Ley de Cuba.

Señoras y señores, la geopolítica y el Derecho internacional privado forman una inmejorable pareja de ases, pero el resultado de la jugada es incierto, así que faites vos jeux, place your bets...!

Legal Materials, 1996, pp. 1322-1334; F.J. GARCIMARTíN ALFÉREZ, "El régimen normativo de las transacciones privadas internacionales: una aproximación económica", REDI, 1995, pp. 11-39; F.J. GarcimarTín Alférez, "El coste de la Ley Helms-Burton para las empresas españolas", Derecho de los Negocios, Año 7, no 72, 1996, pp. 13-27.

${ }^{37}$ Reglamento (CE) No 864/2007 del Parlamento Europeo y del Consejo de 11 de julio de 2007 relativo a la ley aplicable a las obligaciones extracontractuales (DOUE L 199 de 31 julio 2007). 